\title{
The Meaning Making Model Applied to Community-Dwelling Adults with Chronic Pain
}

\author{
Alexandra Ferreira-Valente $\mathbb{D}^{1,2}$ \\ Fernando Fontes (iD ${ }^{3}$ \\ José Pais-Ribeiro (iD) \\ Mark $\mathrm{P}$ Jensen iD ${ }^{2}$ \\ 'William James Center for Research, \\ ISPA - Instituto Universitário, Lisbon, \\ Portugal; ${ }^{2}$ Department of Rehabilitation \\ Medicine, University of Washington, \\ Seattle, WA, USA; ${ }^{3}$ Centre for Social \\ Studies, University of Coimbra, Coimbra, \\ Portugal
}

\begin{abstract}
Purpose: Chronic pain is a multidimensional experience that is influenced by biological, psychological, social, and spiritual factors. The Meaning Making Model is a recent cognitive behavioral model that has been developed to understand how psychosocial factors influence adjustment to stressful events, such as having a chronic illness. This qualitative study aims to understand the potential utility of this model for understanding the role of meaning making in adjustment to chronic pain.
\end{abstract}

Materials and Methods: Eighteen community-dwelling adults with chronic low back pain or chronic pain due to osteoarthritis participated in four focus groups. Participants were asked open-ended questions about their pain experience, pain-related beliefs, meaning of pain, and the perceived association between pain and their meaning in life and sense of purpose. Data were submitted to thematic analysis and the identified themes were considered in light of the Meaning Making Model.

Results: Three overarching themes emerged, each of which included two themes. The first overarching theme - "appraised meaning of pain" - included the themes "causal attributions" and "primary appraisals." The second - "meaning making processes" - included the themes "assimilation" and "accommodation." The third - "meanings made" - included the themes "pain as an opportunity" and "acceptance."

Conclusion: The key themes that emerged as individuals with chronic pain discussed pain and its impact are consistent with those that would be hypothesized as important from the Meaning Making Model, providing preliminary support for the utility of this model in the context of chronic pain. People with chronic pain appear to appraise pain in terms of its cause, controllability, threat, loss, or challenge. When a discrepancy between the appraised meaning of pain and one's global meaning emerged, participants engaged in meaning making processes (accommodation and assimilation), resulting in meanings made, such as a reappraised meaning of pain, perceptions of growth, and acceptance.

Keywords: chronic pain, meaning in life, meaning of pain, thematic analysis

\section{Introduction}

Chronic pain is a significant health condition estimated to be present in $20 \%$ to $30 \%$ of the world's population. ${ }^{1-3}$ It is associated with significant financial costs to society, and both financial and personal costs to those with chronic pain and their families. $^{2-4}$ Pain is a multidimensional subjective experience that both affects and is affected by a number of biological (eg, pain diagnosis), psychological (eg, the meaning of pain, pain-related beliefs, pain coping responses), social (eg, significant others contingent response), and spiritual (eg, type, frequency, and impact of spiritual practices) factors. ${ }^{5-10}$ As a result, chronic pain has traditionally been viewed as a cluster of stressors, ${ }^{11,12}$ consisting of the distress associated with [1]
Correspondence: Alexandra

Ferreira-Valente

William James Center for Research,

ISPA - Instituto Universitário, Rua Jardim do

Tabaco, $n^{\circ}$ 34, Lisbon, I |49-04I, Portugal

Tel +35 I 969082988

Fax +35I 218860954

Email mafvalente@gmail.com 
the experience of pain, [2] the potential causes of pain, and [3] the negative impacts of pain. ${ }^{13}$

Researchers have developed a number of theoretical models to explain the role that psychosocial factors have in pain and function in individuals with chronic pain. These include, among others, the Operant Model of pain, ${ }^{14}$ the Functional Model, ${ }^{15}$ the Fear-Avoidance model, ${ }^{16,17}$ the Motivational Model, ${ }^{18}$ and a number of cognitive behavioral models and models of stress and stress management (such as Lazarus and Folkman's Transactional Model of Stress and Coping and the Acceptance and Commitment Therapy as they can be applied to chronic pain) which have a long history of being used to understand pain and response to pain. ${ }^{19-27}$ Research performed over the past 50 years are consistent with all of these models.

The Meaning Making Model is a recent cognitive behavioral model that was developed to understand the role of psychosocial factors in adjustment to stressful and traumatic events. ${ }^{28-30}$ As a model of response to stress, it has the potential to make an important contribution to our understanding of response to pain. The Meaning Making Model builds on and expands Lazarus and Folkman's Transactional Model of Stress and Coping. ${ }^{19}$ Lazarus and Folkman's model focuses on the role of primary appraisals (ie, appraising a given event as irrelevant/neutral, benign/ positive or stressful [eg, as being a threat or resulting in a loss]) and secondary appraisals (ie, beliefs about coping options and expected outcomes of coping), as precursors of the coping strategies that are then used to manage stressful events. According to these authors, the way a person appraises an event may be influenced by: [1] individual factors, such as commitments with what is important to the person; [2] beliefs about personal control or existential beliefs; and [3] situational factors, such as the novelty, predictability/uncertainty and timing of events. ${ }^{19,21}$

In 2004, Lazarus's and Folkman's model was applied to chronic pain by Beverly Thorn, giving raise to the Stress-Appraisal-Coping Model of pain. ${ }^{20}$ Thorn's approach postulates that, in people with chronic pain, adjustment is associated with the interaction between a person's individual characteristics, primary appraisals about the pain and pain-related stressors (as a threat, harm/loss or challenge), secondary appraisals (eg, beliefs about pain and about one's control over pain, catastrophizing), and pain coping responses. The Meaning Making Model, in turn, focuses: [1] the interaction between the appraised meaning of an event, one's core beliefs about the world and about the self, one's goals in life, and one's subjective sense of meaning, in determining if an event will elicit stress; and [2] the reappraisal of meaning as a key strategy for coping with a stressful event.

The basic tenets of the Meaning Making Model were summarized by Park in an integrative review of the meaning making literature. ${ }^{28}$ According to Park's formulation, all people have a "global meaning," consisting of orienting systems made up of [1] core beliefs or schemas about the world, the self, and the self-in-world (ie, relatively stable ways of interpreting one's experiences of the world, comprising one's views about the self and about justice, coherence and predictability of the world and of events, among others); [2] global goals (ie, those ideals, states, events or outcomes that one desires to obtain or to maintain); and [3] a subjective sense of purpose (ie, feelings of meaningfulness and a sense that a person has a direction and that her/ his actions are guided towards a certain goal). Global meaning is thought to develop early in life. However, it can be modified as a result of significant life experiences. According to the Meaning Making Model, a person's global meaning is one of the factors influencing how $\mathrm{s} / \mathrm{he}$ appraises a given event. These event-specific appraisals are referred to as "situational meanings" in the model.

As Park explains, ${ }^{28}$ situational meaning "refers to meaning in the context of a particular environmental encounter" (p. 258). It includes a set of processes and outcomes that initiate when a potentially stressful event occurs, comprising: [1] the attribution of a meaning to the event, referred to as "appraised meaning"; [2] the evaluation of discrepancies between one's global meaning and the appraised meaning of a such an event; and [3] meaning making processes. Appraised meaning of an event includes, for example, appraisals about: [1] the causes of an event (causal attributions); [2] the extent to which an event reflects a threat, a loss or a challenge (ie, primary appraisals); [3] the degree of controllability of the event; and [4] the short- and long-term implications of the event. Both an individual's global meaning and the characteristics of the stressful event influence how an event is appraised. According to this model, after someone appraises an event with respect to its meaning, s/he then initiate an evaluation process assessing the congruence or discrepancy between the appraised meaning of the event and her/his global meaning. Any discrepancy between the appraised meaning and the individual's global meaning elicits distress, which continues until and if the person 
initiates a "meaning making process" that reduces the discrepancy. The meaning making process may be either automatic (ie, unconscious) or deliberate (ie, conscious effortful processing). It includes a search for comprehensibility/significance and cognitive or emotional processing. This process can then result in a new or changed situational and/or global meaning.

Meaning making processes that involve changing situational meaning are referred to as "assimilation," while those entailing a change in global meaning are called "accommodation." The outputs, or outcomes, of the meaning making process are called "meanings made" (eg, a sense of having made sense, a perception of personal growth or of positive life changes, acceptance, a new/ changed appraised meaning, a new/changed global meaning). In the context of the Meaning Making Model, and unlike other well-established cognitive behavioral models (such as the Acceptance and Commitment Therapy), acceptance - the extent to which a person states to have reached a sense of acceptance or to have come to terms with a given event - is considered an outcome of the meaning-centered coping process, rather than a (sub)process itself. ${ }^{25,27,28}$

The constructs and basic tenets of the Meaning Making Model might be illustrated by a fictitious example based on the findings of previous research..$^{28,30}$ Imagine a 30 years old married woman who is employed full time. As is the case of many people, she believes in a benevolent, just and predictable world, in which good things happen often, and more often to good people (core beliefs about the world). As a core belief about the (her)self, she views herself as a fair, conscientious, and lovable person, who is in control of her own life. Thus, she tends to expect that life and life events will unfold favorably (ie, core beliefs about the self-in-world). This woman hopes to have children in the coming years, and effectively reconcile her family life with her career (global goals). These goals drive her. Life makes sense (sense of purpose). Taken together, these beliefs, goals, and sense of purpose constitute her global meaning. When she was diagnosed with an aggressive form of breast cancer (situation/event), she realized that, because of the course of treatment, she would need to suspend her career plans - at least for some time - and she would most likely not be able to get pregnant (discrepancy between situational meaning and her global goals). She could not understand how it was possible that such an unfortunate and unpredictable event could happen to her (discrepancy between situational meaning and her core beliefs). This condition represented a threat (appraised meaning of the event) to the fulfilment of her goals, and to her identity as a competent woman in control of her life. Being a cancer survivor, she realized that she would probably have to find new ways of fulfilling her life goals (meaning making process, accommodation). She and her husband decided to adopt a child (meanings made, changed goals). As she received cancer treatment, she became closer to her family, more empathetic, patient, and resilient. After she and her husband adopted a child, her life made sense again (meanings made, perception of growth or positive life changes). Taken together, these constitute both her situational meaning (appraised meaning of event, evaluation of the discrepancy between situational meaning and one's global meaning, and meaning making process), and the outcomes or outputs of the meaning making process (meanings made).

While these constructs may be similar to those of other theoretical models, such as cognitive behavioral models and the model underlying Acceptance and Commitment Therapy, the Meaning Making Model provides, we think, a useful framework understanding how people adapt to meaning-centered pain interventions. The Meaning Making Model could also inform the development of new interventions that facilitate adaptive meaning making, and provide an additional treatment option for individuals who are not responsive to either Cognitive Behavioral Therapy or Acceptance and Commitment Therapy.

A treatment that is informed by the Meaning Making Model could potentially differ in important ways from Cognitive Behavioral Therapy and other established treatments. For example, with Cognitive Behavioral Therapy, individuals are taught behavioral and cognitive skills to monitor and change behavioral and cognitive responses to pain from "maladaptive" to "adaptive" ones using very specific strategies, such as cognitive worksheets. With Acceptance and Commitment Therapy, individuals are taught mindfulness strategies for reducing the extent to which they are "fused to" (or respond to) their thoughts. However, treatments based on the Meaning Making Model, including Logotherapy (or meaning-centered therapy, is an approach to psychotherapy initially proposed by Viktor Frankl focusing on human predicament to help a person to overcome existential crisis), ${ }^{31}$ are future-oriented treatments. Rather than focusing on the reduction of symptoms, these treatments focus on people's personal freedom, strengths, meaning and purpose in life, placing the responsibility for 
and control over change and responses to circumstances on the person. Emphasis is placed on the person's potential to transform suffering and guilt into achievement and meaningful actions through dereflection (or self-transcendence), self-distancing, paradoxical intention, and Socratic dialogue. Table 1 summarizes and contrasts the basic principles of the Meaning Making Model with other well-established approaches to chronic pain, including the Stress-AppraisalCoping Model of pain and the Acceptance and Commitment Therapy. ${ }^{20,22,24,25,28}$

Although the Meaning Making Model is well-developed, empirical research testing the basic tenets of theory is limited. The research that has been conducted provides some support for some aspects of the model in individuals who have experienced traumatic events, such as refugees, ${ }^{32}$ bereaved people,${ }^{33-38}$ caregivers, ${ }^{38-40}$ and individuals with cancer. ${ }^{41-43}$ Although statistically significant positive effects of meaningmaking and of meanings made on adjustment are not always found, ${ }^{40,43}$ findings from a number of studies suggest that both global meaning and the meaning attributed to stressful events are relevant factors that interact with individual's personal strengths and coping responses, which in turn, influence how well the person adjusts to the stressor. ${ }^{30,34-37,39,42,44}$ The potential utility of the Meaning Making Model for understanding the role the meaning in life and the meaning of pain play in individuals with chronic pain is yet to be examined. The current study aims to evaluate the potential relevance of the Meaning Making Model for understanding the role the global meaning and the meaning of pain play in pain experience of people with chronic pain, through the analysis of the responses to focus group interviews in people with chronic pain. While we did not anticipate that the themes that would be identified from the analyses would necessarily be unique to the Meaning Making Model, we sought to determine if [1] any themes that would be identified would be inconsistent with the Meaning Making Model or [2] any themes central to the Meaning Making Model would not be identified.

\section{Materials and Methods}

\section{Participants}

The study sample was one of convenience, enrolling individuals who participated in a cross-cultural study directed at studying the similarities and differences between individuals from different countries (Portugal vs USA) with respect to pain coping responses, pain-related beliefs, and the meaning of pain. The current manuscript results from a secondary analysis of the data corpus from this study, limited to the participants from the USA. One paper has already been published using data from the original broader study, ${ }^{45}$ and others are planned.

Participants were community-dwelling (ie, outpatients living independently in the community) adults with chronic low back pain or chronic pain due to osteoarthritis. Inclusion criteria were: [1] being at least 18 years old; [2] having been born in the United States of America; [3] experiencing significant, disabling, bothersome pain most of the days $(50 \%$ or more of the days) for at least 12 months; and [4] having either low back pain or pain associated with osteoarthritis, the two most common types/causes of chronic pain. ${ }^{2,46}$ We opted to include individuals who had chronic pain for at least 12 months in order to maximize the chances that participants' thoughts about their pain and the meaning of pain were well established, and that any accommodation and assimilation may have occurred. Prospective participants with [1] cognitive impairment that would prevent participation or [2] significant psychopathology (eg, active suicidal intention) were excluded.

The study sample consisted of 18 participants. As shown in Table 2, most participants were men $(\mathrm{n}=10)$, aged between 39 and 80 years old $(M=64.78, S D=10.65)$. Half of the study participants were married or in a domestic partnership ( $\mathrm{n}=9$ ). All participants had completed high school, and most had a college degree $(n=14)$. Only three participants were employed full time, while 12 were retired and the remaining were either unemployed or had other professional status.

\section{Measures}

Study participants were asked to complete a sociodemographic and pain history questionnaire and self-report measures of pain intensity and pain interference for descriptive purposes. An open-ended semi-structured interview schedule was developed to elicit information about the participants' pain experience, pain-coping responses, pain-related beliefs, meaning of pain, and the perceived association between pain and their meaning in life and their sense of purpose.

\section{Pain Intensity}

Average pain intensity in the previous 24-hours was assessed using an 11-point Numeric Rating Scale (NRS), where 0 indicated "No pain" and 10 indicated "Worst imaginable pain." Previous research supports the validity of the NRS as a measure of pain intensity. ${ }^{47}$ 
Table I Basic Principles of Cognitive Behavioral Therapy, the Stress-Appraisal-Coping Model of Pain, the Acceptance and Commitment Therapy, and the Meaning Making Model

\begin{tabular}{|c|c|c|c|c|}
\hline & $\begin{array}{l}\text { Cognitive Behavioral } \\
\text { Therapy }\end{array}$ & $\begin{array}{l}\text { Stress-Appraisal-Coping } \\
\text { Model of Pain' }\end{array}$ & $\begin{array}{l}\text { Acceptance and } \\
\text { Commitment Therapy }\end{array}$ & Meaning Making Model \\
\hline $\begin{array}{l}\text { Basic } \\
\text { philosophies }\end{array}$ & $\begin{array}{l}\text { The way a person responds } \\
\text { (physiologically, emotionally/ } \\
\text { affectively, and behaviorally) to } \\
\text { a given event (eg, pain) is } \\
\text { influenced by her/his thoughts } \\
\text { (about the event). } \\
\text { A person's way of thinking and } \\
\text { their thoughts) are influenced } \\
\text { by her/his (core) beliefs, which } \\
\text { are rooted in one's early life } \\
\text { experiences. }\end{array}$ & $\begin{array}{l}\text { The way a person copes with } \\
\text { pain and its impact is } \\
\text { determined by the transaction } \\
\text { between the way s/he appraises } \\
\text { pain (and its impact) and her/his } \\
\text { (intermediate) beliefs (about } \\
\text { pain, one's control over pain, } \\
\text { catastrophizing, other). } \\
\text { These appraisals are influenced } \\
\text { by the person's individual } \\
\text { characteristics (eg, biological } \\
\text { state, personality, core beliefs, } \\
\text { social roles). }\end{array}$ & $\begin{array}{l}\text { Accepting thoughts and feelings } \\
\text { as they are (instead of fighting } \\
\text { against them) makes it easier to } \\
\text { focus in achieving one's most } \\
\text { valued goals. }\end{array}$ & $\begin{array}{l}\text { The way a person appraises an } \\
\text { event is influenced by the } \\
\text { characteristics of the event itself } \\
\text { and a person's core beliefs (about } \\
\text { the world, the self, and the self-in- } \\
\text { world), goals in life, and sense of } \\
\text { purpose. } \\
\text { Distress produced by } \\
\text { a discrepancy between the way } \\
\text { a person appraises an event and } \\
\text { the person's core beliefs, goals, or } \\
\text { sense of purpose can be reduced } \\
\text { through meaning-centered coping } \\
\text { (ie, meaning making processes) } \\
\text { altering either the way the person } \\
\text { appraises the event, the person's } \\
\text { core beliefs, goals, or sense of } \\
\text { purpose. }\end{array}$ \\
\hline $\begin{array}{l}\text { Cause(s) of } \\
\text { (dis)stress or } \\
\text { maladjustment }\end{array}$ & $\begin{array}{l}\text { Negative, unrealistic and faulty } \\
\text { thinking - cognitive distortions } \\
\text { and maladaptive (core) beliefs - } \\
\text { leads to distress and } \\
\text { maladaptive behavioral } \\
\text { responses to events. }\end{array}$ & $\begin{array}{l}\text { Negative, unrealistic and faulty } \\
\text { thinking - cognitive distortions } \\
\text { and maladaptive (core) beliefs - } \\
\text { leads to distress and } \\
\text { maladaptive behavioral } \\
\text { responses to pain. }\end{array}$ & $\begin{array}{l}\text { Experiential avoidance, } \\
\text { cognitive entanglement, and } \\
\text { psychological inflexibility } \\
\text { contribute to distress and an } \\
\text { inability to achieve one's most } \\
\text { valued goals. }\end{array}$ & $\begin{array}{l}\text { A discrepancy between the way } \\
\text { a person appraises an event and } \\
\text { the person's core beliefs, goals, } \\
\text { or sense of purpose. }\end{array}$ \\
\hline $\begin{array}{l}\text { Goals/Course } \\
\text { of treatment }\end{array}$ & $\begin{array}{l}\text { A person's maladaptive (and } \\
\text { often automatic) thoughts and } \\
\text { (intermediate and core) beliefs } \\
\text { may be changed/corrected by } \\
\text { learning and practicing } \\
\text { behavioral and cognitive skills. }\end{array}$ & $\begin{array}{l}\text { A person's maladaptive } \\
\text { appraisals, beliefs, and behavior } \\
\text { may be changed/corrected by } \\
\text { learning and practicing } \\
\text { behavioral and cognitive skills }\end{array}$ & $\begin{array}{l}\text { Teach the person strategies to } \\
\text { help them notice and accept } \\
\text { their experience as it is - } \\
\text { without judgement - making it } \\
\text { easier for the person to make } \\
\text { decisions and take actions } \\
\text { consistent with their valued } \\
\text { goals. }\end{array}$ & $\begin{array}{l}\text { Nurture beliefs about personal } \\
\text { freedom, strengths, meaning, and } \\
\text { purpose in life. Specific strategies } \\
\text { may include dereflection (or self- } \\
\text { transcendence), self-distancing, } \\
\text { paradoxical intention, and } \\
\text { Socratic dialogue. An example of } \\
\text { a meaning-centered intervention } \\
\text { program is logotherapy. }\end{array}$ \\
\hline Key concepts & $\begin{array}{l}\text { - (Negative) Automatic } \\
\text { thoughts and cognitive } \\
\text { processes } \\
\text { - Cognitive distortions } \\
\text { - Intermediate beliefs } \\
\text { - Core beliefs/Cognitive } \\
\text { structures/Schemas } \\
\text { - Emotions/Affect } \\
\text { Behavior }\end{array}$ & $\begin{array}{l}\text { - Individual characteristics } \\
\text { (biological state, personality, } \\
\text { mental health, social roles, } \\
\text { core beliefs) } \\
\text { - Primary appraisals (threat, } \\
\text { harm/loss, challenge) } \\
\text { - Secondary appraisals } \\
\text { (cognitive errors, beliefs, } \\
\text { efficacy) } \\
\text { - Coping }\end{array}$ & $\begin{array}{l}\text { - Present vs Past vs Future } \\
\text { - Acceptance vs Experiential } \\
\text { avoidance } \\
\text { - Defusion vs Cognitive fusion } \\
\text { - Self as a context vs Self as } \\
\text { a content } \\
\text { - Committed action vs Inaction } \\
\text { Values vs Lack of direction }\end{array}$ & $\begin{array}{l}\text { - Global meaning (core beliefs, } \\
\text { global goals, subjective sense } \\
\text { of meaning/purpose) } \\
\text { - Situational meaning } \\
\text { - Appraised event meaning } \\
\text { - Meaning making processes } \\
\text { (eg, assimilation, } \\
\text { accommodation) } \\
\text { - Meanings made (eg, sense of } \\
\text { having "made sense", } \\
\text { acceptance, perception of } \\
\text { growth or positive life } \\
\text { changes, changed identity or } \\
\text { beliefs or goals, etc.) }\end{array}$ \\
\hline
\end{tabular}

Notes: This model corresponds to Beverly Thorn's (2004) application of the Lazarus and Folkman's (1984, 1987) Transactional Model of Stress and Coping to chronic pain. 
Table 2 Study Sample Characteristics

\begin{tabular}{|l|r|r|r|r|r|r|}
\hline & $\mathbf{n}$ & \% & M & SD & Min & Max \\
\hline Sex (women) & 8 & 44.4 & - & - & - & - \\
\hline Age & - & & 64.78 & 10.65 & 39 & 80 \\
\hline Marital status & & & - & - & - & - \\
Single & 3 & 16.7 & & & & \\
Married/ Domestic partnership & 9 & 50 & & & & \\
Divorced/ Separate & 3 & 16.7 & & & & \\
Widowed & 3 & 16.7 & & & & \\
\hline Education Level & & & - & - & - & - \\
Post-secondary education & 4 & 22.2 & & & & \\
Bachelors degree & 6 & 33.3 & & & & \\
Masters degree & 6 & 33.3 & & & & \\
Doctoral degree & 2 & 11.1 & & & & \\
\hline Employment status & & & - & - & - & - \\
Employed & 3 & 16.7 & & & & \\
Unemployed & 1 & 5.6 & & & & \\
Retired & 12 & 66.7 & & & & \\
Other & 2 & 11.1 & & & & \\
\hline Diagnosed Pain-related & & & & & & \\
condition(s) & & & & \\
Osteoarthritis & 13 & 72.2 & & & & \\
Trauma/fracture-related pain & 8 & 44.4 & & & & \\
Knee injury/disorder & 11 & 61.1 & & & & \\
Shoulder injury/disorder & 11 & 61.1 & & & & \\
Intervertebral disc disorder & 12 & 66.7 & & & & \\
Other spinal disorder & 7 & 38.9 & & & & \\
\hline 0-I0 NRS Pain intensity & - & & 4.89 & 2.30 & 1 & 8.57 \\
\hline BPI Pain interference & - & & 4.87 & 2.70 & 0.43 & \\
\hline
\end{tabular}

Abbreviations: NRS, Numerical Rating Scale; BPI, Brief Pain Inventory.

\section{Pain Interference}

Pain interference was assessed using the Brief Pain Inventory (BPI) Interference scale. ${ }^{48}$ This measure asks respondents to report to the degree to which pain interferes with 7 different domains of daily life (general activity, mood, walking ability, normal work, relations with other people, sleep, and enjoyment of life) on an 11-point type of Likert scale, where 0 corresponds to "Does not interfere," and 10 corresponds to "Completely interferes." Previous research supports the reliability and validity of the BPI Interference scale. ${ }^{48}$

\section{Open-Ended Interview Schedule}

An open-ended semi-structured interview schedule (available from the first author) was initially drafted by the first author, and was then discussed with the third and fourth authors. As noted previously, the present study results from a secondary analysis of data corpus from a broader cross-cultural study on chronic pain. Thus, the interview questions were developed based on the cross-cultural research project's aims and on existing literature. However, we reasoned that these questions should also elicit information that may be relevant to the Meaning Making Model. The questions were open-ended and semistructured, allowing the freedom and flexibility to explore themes as they arose to prevent inducing a direction to the participants. Participants were first asked introductory questions about themselves and their pain experience (eg, "Would you tell us about your pain experience?"), followed by and four key-questions about: [1] the way participants cope with pain ("Please make a list of ways in which YOU usually cope with pain. [...] Could each of you please share with us now what you wrote?"); [2] the thoughts they have when in pain ("Take about two minutes and write down the thoughts that tend to come to your mind when you hurt [...]. Let's go around and share what you wrote."); [3] the meaning of pain ("What does pain mean to you?"); and [4] the perceived association between pain and one's meaning in life and sense of purpose ("How do you think your most deeply held values with respect to the meaning you give to life are associated to your response to your pain?"). Probes were used when deemed necessary by the focus-groups facilitators (eg, "When you think of what others have said, does anything else about the meaning of pain to you come to mind?"). For the purpose of the current study, only the key-questions regarding the thoughts participants have when they hurt, the meaning of pain, and the perceived association between pain and one's meaning in life and sense of purpose were considered.

\section{Procedures}

This study was conducted in accordance with the Declaration of Helsinki. The study was approved by the Institutional Review Board (IRB) at the University of Washington (IRB ID: STUDY00004728). Participants were recruited from two databases of individuals from the United States with medical conditions commonly associated with chronic pain, including osteoarthritis and low back pain. The first database is a research participant registry maintained by the University of Washington, and includes individuals who had participated in previous studies at this university, and who had agreed to be contacted again for possible participation in future research studies. The second database is a coding list of people who had 
been seen for pain management at the University of Washington Medical Center.

Prospective participants were sent an invitation letter summarizing the study aims and procedures, and instructing interested individuals to contact the research team by phone or email. In addition, study staff contacted prospective participants by phone during the two weeks after the invitation letter was sent, to confirm prospective participants' interest in participating in the study and screen interested individuals' eligibility to participate.

Eligible and interested individuals were provided a full description of the study aims and procedures and signed an informed consent form, including consent for publication of anonymized responses. Participants were invited to participate in one of the four in-person focus groups. The use of focus groups was chosen in order to explore, gather, and better understand participants' views, feelings, thoughts, and experiences in a more naturalistic, permissive, nonthreatening environment and in a cost-effective way than would be possible with individual interviews. ${ }^{49,50}$ Focus groups permit a confrontation of perspectives between the participants, which tends to promote greater self-disclosure, and facilitate the expression of ideas and experiences that might be left underdeveloped in an individual interview. ${ }^{49,50}$ Each group session began with a brief discussion of the purposes and rules (eg, confidentiality, anonymity) of the focus groups. Participants were then asked open-ended questions about their pain experience, about the way they cope with their pain, about the thoughts they have when in pain, about the meaning of pain and about the perceived association between pain and one's meaning in life and sense of purpose. Following Krueger and Casey's recommendations, we initially planned for a minimum of three focus groups. ${ }^{49}$ No new ideas emerged in the third focus group that had not been expressed in the first two, indicating that by the third focus group, we had achieved saturation of information. However, to confirm this, we scheduled and conducted a fourth focus group. As no new data emerged from the fourth focus group, we did not conduct a fifth focus group. The composition and characteristics of the participants in each focus group is presented in Table 3.

The focus groups were co-facilitated by the first author and one trained research assistant. Focus groups were audio- and video-recorded, and transcribed verbatim, to allow for a detailed review of the content. Focus groups transcripts were subjected to Braun and Clarke's six-phase reflexive thematic analysis. ${ }^{51-54}$ As suggested by Braun and Clarke, ${ }^{51-53}$ we adopted a flexible and hybrid approach to the thematic analysis, following a predominantly bottom-up approach in the first through third phases (ie, familiarizing with data, generating initial codes, and searching for themes), to allow for the potential identification of themes that might not represent the constructs and tenets of the Meaning Making Model, and to allow greater depth in the comprehension about the way participants made sense of the themes. Specifically, codes were identified based on the raw data without an a priori coding system. The fourth and fifth phases of thematic analysis (ie, reviewing themes, and defining and naming themes) were closely informed by the Meaning Making Model literature, and performed in a close dialogue with this model. Although a predominantly theoretical or topdown approach throughout all the phases of thematic analysis, informed by previous research regarding the Meaning Making Model, ${ }^{28,30}$ was considered, we opted to use a hybrid approach to enable a higher degree of flexibility and depth in the data analysis, and to capture more nuanced relationships between different meanings that a top-down approach might miss. ${ }^{51,52,55,56}$

Reflexive thematic analysis was performed independently by the first author and one trained research assistant (who was not present at the focus groups), using data from all focus groups. The two coders individually read, analyzed, and performed the initial coding of the transcripts. Coders used predominantly semantic coding, and latent coding occasionally for richer descriptions. Discrepancies were reconciled by consensus during a consensus meeting. Two researchers (the first and second authors) reviewed the initial codes and themes through an ongoing iterative process, followed by a discussion with the senior author about the naming and definition of the final themes. The codes and the main themes identified within the data were discussed with the remaining team members.

\section{Results}

The analysis of the focus groups discussions allowed the identification of several themes. These included three overarching themes: [1] "appraised meaning of pain;" [2] "meaning making processes;" and [3] "meanings made." Each overarching theme encompassed two related themes. The first overarching theme encompassed the themes "causal attributions" and "primary appraisals." The second encompassed the two themes "assimilation" and "accommodation." The third overarching theme encompassed the themes "pain as an opportunity," and "acceptance." Each of these themes 
Table 3 Focus Groups Composition

\begin{tabular}{|c|c|c|c|c|}
\hline & \# Participant & Sex & Age & Marital Status \\
\hline \multirow[t]{5}{*}{ Group I } & Participant I & Male & 64 & Married/ Domestic partnership \\
\hline & Participant 2 & Male & 58 & Married/ Domestic partnership \\
\hline & Participant 3 & Female & 59 & Divorced/Separated \\
\hline & Participant 4 & Female & 75 & Widowed \\
\hline & Participant 5 & Male & 39 & Single \\
\hline \multirow[t]{4}{*}{ Group 2} & Participant 6 & Female & 63 & Divorced/Separated \\
\hline & Participant 7 & Male & 69 & Married/ Domestic partnership \\
\hline & Participant 8 & Male & 71 & Married/ Domestic partnership \\
\hline & Participant 9 & Female & 80 & Single \\
\hline \multirow[t]{3}{*}{ Group 3} & Participant 10 & Female & 67 & Widowed \\
\hline & Participant II & Male & 65 & Married/ Domestic partnership \\
\hline & Participant 12 & Male & 78 & Married/ Domestic partnership \\
\hline \multirow[t]{6}{*}{ Group 4} & Participant 13 & Male & 71 & Married/ Domestic partnership \\
\hline & Participant I4 & Female & 49 & Divorced/Separated \\
\hline & Participant I5 & Male & 76 & Married/ Domestic partnership \\
\hline & Participant 16 & Male & 61 & Single \\
\hline & Participant 17 & Female & 69 & Married/ Domestic partnership \\
\hline & Participant 18 & Female & 52 & Widowed \\
\hline
\end{tabular}

is consistent with the Meaning Making Model's key concepts. However, three of the concepts hypothesized to be important to the Meaning Making model were not identified. These refer to the nature of meaning making processes as [1] being either automatic or deliberate, [2] involving a search for comprehensibility and significance, and [3] involving either or both cognitive processing and emotional processing. Figure 1 presents the thematic map depicting the overarching themes and subthemes.

\section{Appraised Meaning of Pain}

One overarching theme that was identified reflected the ways that pain is perceived by the study participants in terms of its causes ("causal attributions"), and the shortand long-term implications of chronic pain as they were associated with the extent to which pain reflects a threat, a loss, or challenge, and with the degree of controllability ("primary appraisals"). Both themes represent cognitive appraisals through which participants evaluate the meaning of pain with respect to its personal significance.

\section{Causal Attributions}

Pain was highlighted most often as a negative message about a dysfunctional body whose integrity and balance has been compromised or challenged. Most frequently, participants attributed the cause of their pain to biological factors, such as a tissue damage, a previous injury, or an ongoing medical condition, leading them to cope with their pain and pain-related condition by searching for health care. Many participants expressed the view that pain means that something is wrong in one's body. As one participant verbalized:

It seems to be some kind of physical cause. I mean, its nerves transmitting this pain to your brain. Believe it or not, is doing nerves to our body [laughing] because it just tells me that something is wrong in the body that causes simple pain. But the pain tells me that something is wrong.

(Group 2, Participant 7)

Pain is, thus, viewed as an annoying and/or unsettling alarm or warning that harm is occurring, because of an illness or an injury, which may be associated with one's lifestyle, or physical activity. Pain was also often viewed as being caused by a lack of physical, emotional and activity balance. In turn, these causal attributions directly influenced the way participants tried to prevent or cope with pain flares. For example, pain was sometimes attributed either to too much or too little activity, leading participants to attempt to balance activity level. One participant said, for example,

And the other side of that too is overuse. Overdoing it. I am not good at necessarily finding the balance that I need 


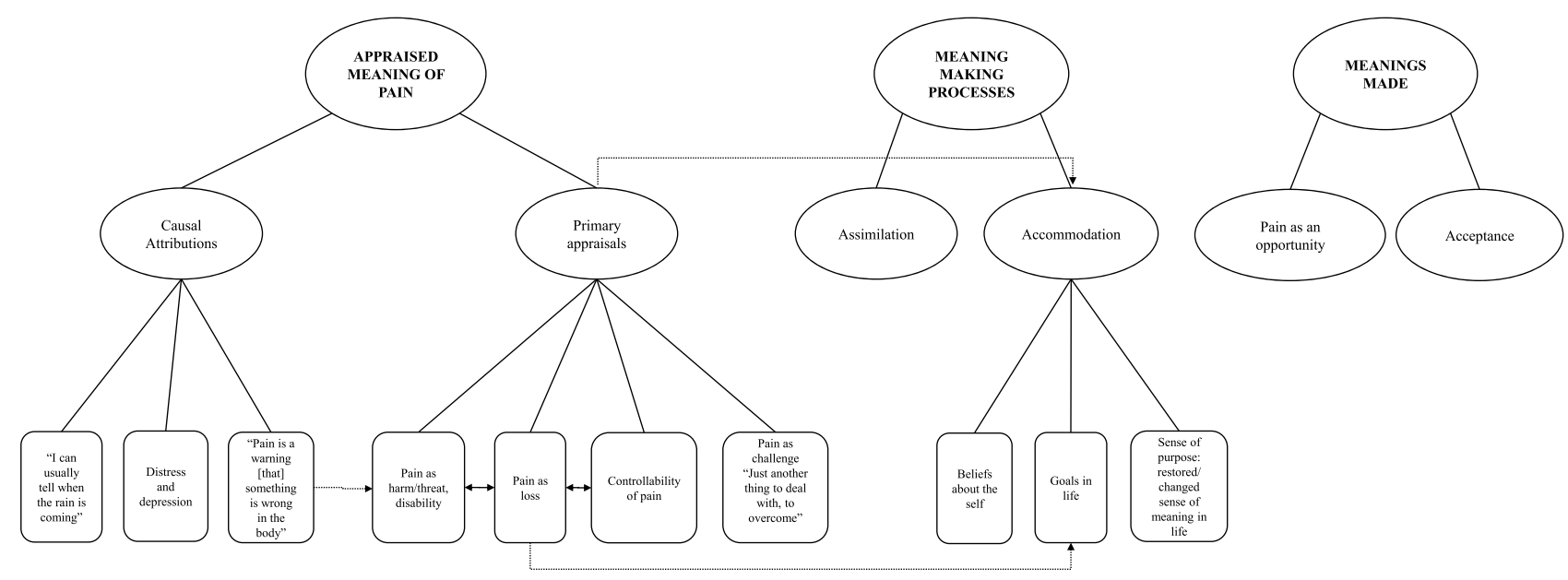

Figure I Thematic map depicting the overarching themes and subthemes.

Notes: $\leftrightarrow$ Bidirectional association between the sub-themes within the same theme. $\rightarrow$ Unidirectional association between the (sub-)themes within the different (overarching) themes.

to, because I want to do more than I seem to be able to do now. ... [pause] So, pain is a warning (Group 2, Participant 7);

Another said,

Inactivity makes the pain worse, if you're ... [pause] but then, you know, people ... when you force to start getting active again, but I think in the end activity helps, you know ... doing something. That's what I'm trying to do now. Because when I was doing nothing except sitting, the pain was like really bad. (Group 2, Participant 6)

Another participant said,

At least for those of us who try to do physical things and physical exercise, even though it has nickels of consequences, at some point, at the same time, you get the positive benefits of keeping everything on. (Group 4, Participant 16)

That said, the participants noted that an optimal level of activity is not always possible, due to social and economic constraints, such as the lack of social support or the need to continue working for economic reasons.

Less frequently, study participants also attributed pain flares to psychological factors, such as emotional states. The participants who expressed this idea recognized that pain and emotions often influence each other. When in bad mood, many participants reported that they tend to ruminate, focus on the pain, and catastrophize. As a result, they then become less active, and notice an increase in pain intensity. As one participant summarized, "And also, strong emotion. If I am upset about something the pain seems worse" (Group 3, Participant 10). Another participant said:

Yes. I find that maybe it is because less activity in my life, but what was happening with me was ... I will be flashing back on to negative things that happened in my life that I hadn't thought about in years. And the other thing like catastrophizing, like having all these fears. Being old and unable to take care of myself and ending up in a nursing home. That's how like emotions and pain are connected. (Group 2, Participant 6)

Some participants highlighted that pain intensity may vary as a result of adverse weather conditions or anticipating weather change:

I definitely agree. I can usually tell when the rain is coming because my joints really start acting up. And the heat, the nice warmth, does definitely help a lot. Hot tubs are God sent. I wish I had one [laughing], especially for my lower back. (Group 3, Participant 11)

\section{Primary Appraisals}

This theme highlights the way participants appraise pain, in terms of its threat/harm, loss, challenge and controllability, and assess the implications and impact of pain in their lives. The analyses revealed a significant association between pain and disability. This association has important consequences in participants' self-esteem and in the way participants evaluate their capacities and abilities to participate in society. Negative images of disability impact the way that the participants view themselves. Pain, therefore, was often appraised as 
a threat to one's individuality, to autonomy, and to an overall enjoyment of life. Participants often noted that pain significantly interferes with their ability to perform household chores, maintain professional activities, engage in meaningful and pleasurable activities, and maintain the desired levels of participation in social and family life. Thus, for many, pain is viewed as something which limits their ability to achieve their goals, limiting their sense of purpose. In this way, pain represents a clear threat to global meaning, and can create a discrepancy between pain's appraised meaning (as threat/harm and disability) and the person's global meaning (ie, the way participants view and value themselves, their ability to pursue their global goals and their subjective sense of purpose in life), resulting in distress. The specific negative emotional states described by the participants resulting from the negative impact of pain on global meaning included feelings of helplessness, discouragement, disappointment, frustration, shame, guilt and self-pity.

In line with the pervasive appraisal of pain as harm/ threat and its association with disability, the analysis also revealed pain as a limitation to individuality, as participants often perceive themselves as being less worthy than others without chronic pain or disability, due to their painrelated activity limitation. Thus, pain seems to be associated with a risk of an implicit sense of loss, including loss of one's financial stability, loss of one's worth, loss of one's social roles, and loss of one's ability to pursue one's goals and dreams. For example, one participant said:

I think many times - I'm probably a little bit in the same boat - when I became disabled, I was a police officer, and that was the end of my career. So, and then I found myself in a horrific bureaucratic system and which every excuse in the world could be given for why I couldn't go back to do anything else. (Group 4, Participant 16)

Another participant said:

I'm 58, we live in a large home, and over the years I've been always physically active, and been able to do a lot of things around the house, and I can't do those things anymore. And so, my wife, who is 60 , she is in a better physical shape than I am, fortunately. She picks up all these things, she does all the traditionally male things around our house. She mows the lawn, she takes care of the yard, she does all that stuff. I have my kids coming in [to] help us. (...) I used to feel bad about having to do that, really feel a lot of self-pity. (Group 1, Participant 2)
Another participant made this self-devaluating process even clearer, contrasting his previous condition without chronic pain and his current condition, as he put it:

I'm raising my two grandsons and I cannot be out of commission. I have to be ... I'm just angry, I have a little bit of what is me, and then I wonder how the hell I am going to raise these two kids. I feel like a failure, I get frustrated with the pain that is preventing simple movement. (Group 4, Participant 17)

Given the losses associated with pain, pain was often seen by participants as a source of oppression, a threat to participants' physical function and autonomy. One participant observed, "I was diagnosed with a whole-body impairment. (...) So, when I started to hurt ... I was completely dependent. (...) It is oppression" (Group 1, Participant 5). Yet another shared,

I get angry at myself - that I can't do what I want to do. And frustrated that having this pain has caused me not to able to do what I want to do. Disappointment some sort into that. (Group 3, Participant 11)

By threatening participants' core beliefs about the self as autonomous and productive, as well as their sense that life has a purpose, appraisals of pain as loss entail a discrepancy between situational meaning and global meaning, which results in distress.

Normalization of pain, although occurring less frequently, also emerged from the focus groups' discussions. For example, pain was sometimes described as a natural part of life - a "here-and-now" experience that people with chronic pain need to face as they face other challenges. As one participant acknowledged:

I guess I've always kind of looked at life as just a series of challenges that people go through. And everybody's challenges are different. Getting older is another one of those challenges. So I don't view the pain as anything negative. I have thought, at times, that well it let me know that I am alive. (Group 3, Participant 12)

Thus, unlike appraisals of pain as resulting in loss, as being harmful or threatening, and/or as a disability, appraising pain as a neutral event (ie, as challenge), does not appear to result in a threat to one's global meaning.

Finally, participants discussed chronic pain with respect to its degree of controllability, in particular with respect to biomedical interventions, such as pain medications, surgery, and pool therapy. A reliance on - or at least 
hope for - the medical model emerged in discussion about the participants' confidence in the rapid advancement of medical science. However, the participants also recognized that there is only so much healthcare providers can do to manage pain at the present. This sometimes contributed to feelings of hopeless and disoriented:

So I go ... and I feel the medical profession ... that they don't know what to do with me. How can I, what can, I don't know ... my feelings are sadness. Not regret for things in my past, but I'm not as hopeful. (Group 2, Participant 9)

The perceived uncontrollability of pain, and the uncertainty that it entails, is discrepant with a core belief of the world as good, predictable, just, and fair (ie, good things happen more frequently than bad thing; good things happen to good people). This may explain distress - in the form of feeling helplessness, hopelessness and anger experienced by those participants who declared themselves, medicine and providers to be limited in their ability to cure the pain. As one of the participants puts it:

I often get kind of depressed. I have a sense of hopelessness. I think I have dealt with this for so long and then when the intensity increases there is not really a lot more that can be done. And it makes me feel kind of hopeless, and that becomes helpless and the helplessness feel kind of ... like my family is kind of having to take care of me, which they are happy to do, but that's not what I wanted to be. (Group 1, Participant 2)

\section{Meaning Making Processes}

The second overarching theme reflected how people living with chronic pain engages in meaning making processes that result in changes in their perspective about pain itself, as well as changes in their global meaning. These changes in situational and global meaning represent, respectively, meaning making processes of assimilation and accommodation that are initiated as a way to cope with a perceived discrepancy between situational and global meaning. Thus, two themes were identified: [1] "assimilation"; and [2] “accommodation." (see Figure 1).

\section{Assimilation}

Some participants coped with distress caused by the discrepancy between situational meaning and global meaning by engaging in assimilation meaning making processes. This assimilation process entails a change in participant's perspective about pain over time - not the output or the outcome of such a meaning making process. However, despite the lack of an explicit in-depth exploration of the comparison between the content of the former and newer appraised meaning of pain, this process of change in the perceived meaning of pain was perceived by some participants as a way to achieve a positive outcome. In fact, at least to some extent, the positive outcome of a situation (ie, pain) depends in part on one's perspective. As one participant shared,

Well, my perspective of it has changed over time for sure. And so ... I used to think about it [pain] ... have self-pity and things like that or obsess too much about it. But (...) I think I'm getting better at doing, is thinking about it [pain] as an opportunity. (Group 1, Participant 2)

Another participant noted:

So, I spend more time now, when I encounter those painful situations, changing ... thinking about my perspective. Like in this situation: what can I think about it differently that's going to lead me to a possible outcome with whatever I'm dealing with right now?. (Group 1, Participant 1)

\section{Accommodation}

Most of the participants, but not all of them, claimed to deal with the distress resulting from a discrepancy between situational meaning and global meaning by engaging in accommodation (ie, meaning making process that entails a change in participants' global meanings, but not the output or the outcome of such a meaning making process itself). For those participants engaging in accommodation, this meaning making process most frequently - but not for all the participants - resulted in an outcome or output with a positive outlook.

Most often, participants did this by changing their global goals. This meaning making process is closely related with the appraisal of pain as loss and harm/threat and disability. As already noted, pain is, for most of the participants, an experience that interferes with the pursuit of one's valued goals. The participants reported that they coped with this inability to pursue goals by deflecting their original goals in life and pursuing other (perhaps similar) goals that are achievable despite pain. For some participants, this resulted in a change in their career path. The following excerpt illustrates this change in professional goals:

I was in my fifties and I had my neck injury and lost the function of my hand for an extent of period of time. Obviously, I could not operate anymore, but I was working 
at the University, and they let me get back to school and get a degree and help service [being a medical teacher]. So, at the last 20 years of my career, I did something similar but actually quite different than what I had done before because I was a gynecologist-obstetrician surgeon. (Group 4, Participant 13)

For other participants, the change was made in personal goals:

My goals, as far as life in general, are to be able to make it up my family comfortable when I am kind of done. I'm okay, and I respect that, but I'm not going to be able to do the hiking that I want to do, or flying to Europe for vacation, because I don't fly well, because it really hurts. So, my wife and I we take the car, we drive around, to see National Parks in the U.S. (Group 2, Participant 7)

Nevertheless, not all participants felt the need to change their goals. In these cases, pain is seen as a challenge a neutral and secondary experience - that exists in the background. Sometimes this means trying to pursue the same goals in life but in a different way, or accepting that they may experience a pain flare afterwards. As one participant mentioned, "I am more like Clinton. I just don't let it stop me. I just recognize I am going to pay a price. And I try, and I work around, so I don't have to ... " (Group 3, Participant 10). Another participant shared, "You just find a way to accomplish your life goals, probably in a different way that you predicted" (Group 3, Participant 11). For these participants, the appraised meaning of pain is not very discrepant from their global meaning. As a result, there is less distress associated with the need to pursue goals in a different way.

Less frequently, participants said that they resolved the discrepancy between situational and global meaning by changing their core beliefs about the self. For these participants, pain-related disability induced changes in one's self-concept; for example, from viewing oneself invincible to viewing oneself as vulnerable: "I thought I was invincible" (Group 4, Participant 15).

Some participants saw pain as a menace to their sense of purpose. For these participants, the meaning making processes of accommodation resulted in a changed sense of purpose. As one participant puts it:

Having a sense of purpose in life is very important to me. I find that pain can interfere with that because my mind became overwhelmed with pain. I have to shift my purpose in life being to take care of myself now. Although I am still somewhat active in the community, I feel a strong desire to be active and speak out for immigrant rights. Because I developed close friendships with people that have immigrated to the United States. Terrible things are happening. So I've gotten involved ... I've gotten involved in signing things (...) my sense of purpose is to become a better person. (Group 2, Participant 6)

On the other hand, for some participants, having a purpose in life and/or a restored sense of purpose, was a resource that increased resilience in the face of pain: "It helps to have a sense of purpose in life. With or without pain if I had no physical pain and no sense of purpose, life would still be sad" (Group 2, Participant 6).

\section{Meanings Made}

The third overarching theme summarizes how living with chronic pain can lead individuals to engage in meaning making processes that sometimes, and only for some participants, resulted in pain acceptance and in personal growth or positive life changes. Two themes were identified: [1] "pain as an opportunity" and [2] "acceptance" (see Figure 1). Both themes correspond to outcomes or outputs of meaning making processes (ie, meanings made) put into place by participants to cope with a perceived discrepancy between situational and global meaning.

\section{Pain as an Opportunity}

The meaning making processes used by participants when coping with the discrepancy between situation and global meaning resulted, at least for some, in a reconfiguration of participants' sense of self, as well as perceptions of growth. For example, some participants perceived themselves to have become more compassionate, more empathetic and more patient towards others. Others reported that they were more resilient, and/or emotionallystronger. As one of the participants put it:

There are also some gifts. One is compassionate and empathetic. I think it makes me a person that ... who can engage with somebody who has whatever form of pain. That is better because of I kind of know what it's like. Maybe not in their particular situation of losing their job or whatever. But it really kind of amps my compassion. And I think that's a gift. (Group 1, Participant 1)

Some participants also mentioned that having chronic pain led them to adopt a healthier lifestyle or improved family relationships. As one participant put it:

I think I'm getting better at doing, is thinking about it as an opportunity. The reason I say that is because, it has 
been a forcing function in how I need to make changes in lots of different ways in my life. For example, when we first start dealing with the physical things and needs, my wife needed to be available more at the house. She was working, she may not love what she was doing, but she was working. So, we decided that we were going to be simple and come home and that way she could focus on taking care of everything at home. Because I make more money. So she could focused on those things and I could focus on my things. It took a shift for us to start thinking about things differently. Now, what that has created is that she is much more active in the community now, which is something she didn't do before. (...) That created a whole new set of opportunities, and now we have grandchildren, and the grandchildren are not here. And she wants to go see these grandchildren. But if she was still working every day of the week, she would be able to do that. (...) If I studied enough, you know ... thinking about what is the pain led me do, led me to a healthier lifestyle overall. (Group 1, Participant 2)

\section{Acceptance}

Although less common, another outcome of the meaning making processes, and thus, a type of made meaning, is a sense of acceptance of chronic pain. Acceptance was viewed by some participants as something that simply exists, and over which people with chronic pain do not have control. It was also viewed as something that can develop over time, and that is associated with the pursuit of new achievable goals in life:

I found that there's a level of radical acceptance of this right now (...). So, that doesn't mean that you've liked or disliked, but this is what it is, and so there's an adjustment of the goals. (...) it took me like almost this whole year and a half to really accept (...) so the goals become different. Like my social activism is different. I used to march a lot. And so now my organization is different and so what I can do is internet work and coalition-building through emails and have meetings at my house where I'm comfortable. (Group 4, Participant 14)

\section{Discussion}

This qualitative study aimed to evaluate the utility of the Meaning Making Model for understanding the role that global meaning and the appraised meaning of pain play in the pain experience of people with chronic pain. The analysis of the focus group discussions allowed the identification of dominant themes, all of which were consistent with the Meaning Making Model. ${ }^{28,30}$

For example, participants referred to the appraised meaning of pain in terms of: [1] its cause (ie, causal attributions); [2] appraisals of pain as harm/threat, loss or challenge and with respect to its controllability; and [3] its short- and long-term implications (ie, primary appraisals). These findings are consistent with previous research that built on the situational meaning theory proposed by Lazarus and Folkman, ${ }^{19}$ and examined the determinants of initial appraisals of an event. ${ }^{57}$ In line with previous findings examining the appraised meaning of pain, ${ }^{17,58,59}$ the participants made attributions about the cause of pain; most often to a medical condition, an injury, or potential injury. This suggests that the participants were most comfortable with a biomedical model of pain, which may be related to the faith participants held in medical solutions for their chronic pain. Another common causal attribution mentioned by the participants was a maladaptive pattern of activity management, such as overuse/excessive activity or inactivity/sedentary lifestyle. This result is consistent with previous research on pain-related beliefs, showing that people with chronic pain often attribute pain flares to their level of physical activity and assume physical activity to be potentially harmful, which, in turn, can lead to fear of movement and avoidance. ${ }^{17,60-62}$ Also consistent with previous research, the study participants sometimes attributed their pain to negative emotional states (eg, distress) and changes in adverse weather conditions. ${ }^{60}$

Although some of the participants perceived their pain as a challenge to be overcome, more often they appraised their pain in terms of its threat/harm and loss. ${ }^{58,59}$ They often referred to their pain in terms of its associated disability, its short- and long-term negative implications for their quality of life, and the extent to which pain is not controllable. Chronic pain emerged as an obstacle limiting one's ability to connect and relate to the world as an autonomous and productive person who is able to pursue and achieve valued goals provides a subjective sense self and purpose in life.

Also, and consistent with the Meaning Making Model, the participants described how a discrepancy between appraised meaning of pain and global meaning resulted in distress that led them to engage in the meaning making processes of assimilation (ie, changing appraised meaning of pain) and/or accommodation (ie, changing one's core beliefs, global goals and/or sense of purpose) that resolves this discrepancy. ${ }^{28,30}$ This finding is also in line with 
previous research performed by Dezutter and colleagues on the meaning of pain, and on the impact of pain in meaning in life. ${ }^{63}$ As found by Dezutter and colleagues, chronic pain can threaten people's subjective sense that life has a meaning and purpose, and their perceptions about what is meaningful, leading to an existential search for meaning in life and a review of one's expectations and goals in life. ${ }^{63}$ However, not always the outcomes or outputs of these meaning making processes was explored indepth by the study participants. Namely, there was a lack of explicit in-depth exploration of the comparison between the specific content of the former and newer appraised meaning of pain. A topic that should be addressed to a further extent in future research.

In line with Park's formulation of the Meaning Making Model, the results of these meaning making processes referred to by study participants (ie, meanings made) included a reappraised meaning of pain, changed global beliefs about the self, changed global goals, changed/ restored sense of meaning in life, changed identify, perceptions of personal growth or positive life changes, and acceptance of chronic pain. ${ }^{28}$ Most frequently, and also in line with the findings of previous research, the study participants referred to a revision of their expectations and goals in life, by pursuing goals that are achievable, yet also often in line with or at least related to their original global goals. ${ }^{63}$

However, inconsistent with the Meaning Making Model, the participants neither referred to the automatic or deliberate nature of the meaning making process, nor to a search for comprehensibility/significance or to cognitive/ emotional processing that might facilitate the meaning making processes. These findings suggest the possibility that the Meaning Making Model may need to be adapted to eliminate these as key components of the model, at least with respect to how individuals cope with chronic pain. Alternatively, it is possible that these components play an important role in adjustment to chronic pain, but did not emerge in the discussions due to a lack of purposeful exploration of these themes during the focus groups. Further qualitative research based on one-on-one in-depth interviews would provide additional understanding of the meaning making processes that are actually used by people with chronic pain.

\section{Research Implications}

Given the preliminary support for many, but not all, of the tenets of the Meaning Making Model in this qualitative study, additional research guided by the model appears warranted. For example, quantitative research is needed to examine how measures of each component of the model (assessing global meaning, situational meanings, and meaning making processes) are associated with pain and function. Measures already exist for some of these components. For example, the Meaning in Life Questionnaire could be used to assess one domain of global meaning, ${ }^{64}$ the Survey of Pain Attitudes scales could be used to assess some of the appraised meanings of (chronic) pain, ${ }^{65}$ and the Global Meaning Violation Scale could be used to assess the presence of discrepancies between appraised meaning and individual's global meaning. ${ }^{66}$

In addition, and in order to facilitate research in this area, new measures may also be useful. For example, although a number of measures assessing core beliefs about the self and the world exist, most of these measures contain items that confound core beliefs with situational meaning. As a result, these measures cannot be used to assess global beliefs. ${ }^{67}$ Also, to our knowledge, a painspecific measure of the meaning making processes, which is hypothesized as a key factor - if not the key factor - in the Meaning Making Model, does not exist. Furthermore, existing measures that have been developed to assess meaning making processes lack evidence supporting their validity. ${ }^{67}$

A second line of research could be conducted that would evaluate the effects of pain treatments on meaning making, and the role that changes in meaning making variables (including meaning making processes) play as mediators of the efficacy of these treatments. Of particular interest could be research on the beneficial effects and mechanisms of treatments that are designed to target meaning making, specifically. For example, meaningcentered psychological interventions, such as logotherapy, ${ }^{68}$ have been shown to be effective for impact measures of personal meaning, psychological well-being, and quality of life in individuals with psychological dysfunction, ${ }^{69}$ and in cancer survivors. ${ }^{70}$ Research examining the effects of logotherapy on meaning making in individuals with chronic pain would be useful.

\section{Limitations}

This study has a number of limitations that should be considered when interpreting the results. First, the sample was recruited using a nonprobabilistic sampling approach of individuals with chronic pain recruited from either (1) an existing registry of individuals willing to participate in 
research maintained by the Department of Rehabilitation Medicine at the University of Washington or (2) a list of people seen for chronic pain treatment in one of the clinics at the University of Washington Medical Center. As a result, the degree to which this sample is representative of the population of people with chronic pain, and the extent to which the study findings can be generalized to this population, cannot be determined. Future studies are needed to establish the generalizability of the current findings. Second, the sample was composed by only 18 participants. However, as previously reported, despite the limited number of participants, neither the third nor the fourth focus group revealed any new themes beyond those that were identified in the first two focus groups. This finding gives us confidence that a larger sample would not have resulted in different results. Nonetheless, we recognize that the sample is composed by participants all living at the state of Washington of the USA. This may have diminished the diversity of experiences and perspectives about one's pain experience. Future studies should recruit higher number of participants living in different regions and states. Third, the sample size was not large enough to evaluate the effects of ethnicity, religious affiliation and practice, or cultural background on the process of meaning making, despite the possibility that any of these could potentially influence this process. Future studies should seek to recruit individuals from a variety of ethnic, religious, and cultural backgrounds, to determine if (and how) meaning making processes might be related to these factors. Fourth, discrepancies relative to the content and interpretation of the content that was coded by the two independent coders were solved through consensus. However, we did not count the number of such discrepancies. Finally, the use of a qualitative design has a number of limitations with respect to evaluating the Meaning Making Model. For example, it does not allow for tests of the causal influence of meaning making processes on measures of function, as would be possible through the use of longitudinal or experimental quantitative studies. Additional quantitative research, as previously discussed, could address this limitation.

\section{Conclusion}

Despite the study's limitations, the findings are generally consistent with the basic principles of the Meaning Making Model. Specifically, findings support the conclusions that: [1] people with chronic pain appraise pain either in terms of its cause and (un)controllability, or as harm/threat, loss or challenge; [2] the appraised meaning of pain - at least among some people with chronic pain can be discrepant from a person's global meaning; [3] when a discrepancy between the appraised meaning of pain and global meaning emerges, people with chronic pain engage in meaning making processes of accommodation and assimilation which then result in; [4] a number of outcomes or meanings made, that include reappraised meaning of pain, changed global meaning, changed identity, perceptions of growth or positive life changes, and acceptance. However, the findings also call into question the potential importance of automatic/deliberate nature of meaning making processes, as well as the search for comprehensibility/significance and cognitive/emotional processing as meaning making processes. Future research evaluation the reliability of these results and testing the basic tenants of the Meaning Making Model in a representative sample of people with chronic pain would be an important next step. If this research provides additional support for the Meaning Making Model, this could not only increase our understanding of how people might effectively adjust to chronic pain, but point to the potential benefits of treatments that target meaning making processes in individuals with chronic pain, such as logotherapy, among others. ${ }^{31}$ The findings indicate that additional research to explore these possibilities is warranted.

\section{Abbreviations}

BPI, Brief Pain Inventory; IRB, Institutional Review Board; NRS, 11-point Numeric Rating Scale.

\section{Acknowledgments}

The authors gratefully acknowledge the Portuguese Foundation for Science and Technology for AFV's FCT post-doctoral grant (SFRH/BPD/121452/2016), FF's Contract under the Transitory Norm (DL57/2016/ CP1341/CT0007) and the William James Center for Research (UIDB/04810/2020). The authors also acknowledge Joy Chan, Sam Battalio, and Emily Stensland for their support in the conduction of the focus groups, Patrícia Costa Pinto for her support in the generation of initial codes of thematic analysis, and Pedro Costa for critically reviewing the manuscript.

\section{Disclosure}

Alexandra Ferreira-Valente reports a grant from the Portuguese Foundation for Science and Technology, 
during the conduct of the study. The authors report no other potential conflicts of interest in this work.

\section{References}

1. Dahlhamer J, Lucas J, Zelaya C, et al. Prevalence of chronic pain and high-impact chronic pain among adults - United States, 2016. MMWR Morb Mortal Wkly Rep. 2018;67(36):1001-1006. doi:10.15585/mmwr.mm6736a2

2. Breivik H, Collett B, Ventafridda V, Cohen R, Gallacher D. Survey of chronic pain in Europe: prevalence, impact on daily life, and treatment. Eur J Pain. 2006;10(4):287. doi:10.1016/j.ejpain.2005.06.009

3. Azevedo LF, Costa-Pereira A, Mendonça L, Dias CC, Castro-Lopes JM. Epidemiology of chronic pain: a population-based nationwide study on its prevalence, characteristics and associated disability in Portugal. $J$ Pain. 2012;13(8):773-783. doi:10.1016/j. jpain.2012.05.012

4. James SL, Abate D, Abate KH, et al. Global, regional, and national incidence, prevalence, and years lived with disability for 354 diseases and injuries for 195 countries and territories, 1990-2017: a systematic analysis for the Global Burden of Disease Study 2017. Lancet. 2018;392(10159):1789-1858. doi:10.1016/S0140-6736(18)32279-7

5. Ferreira-Valente A, Pais-Ribeiro J, Jensen MP, Almeida R. Coping with chronic musculoskeletal pain in Portugal and in the United States: a cross-cultural study. Pain Med. 2011;12(10):1470-1480. doi:10.1111/j.1526-4637.2011.01208.x

6. Ferreira-Valente A, Pais-Ribeiro J, Jensen MP. Association between psychosocial factors and pain intensity, physical functioning, and psychological functioning in patients with chronic pain: a cross-cultural comparison. Clin J Pain. 2014;30(8):713-723. doi:10.1097/AJP.0000000000000027

7. Ferreira-Valente A, Sharma S, Torres S, et al. Does religiosity/spirituality play a role in function, pain-related beliefs, and coping in patients with chronic pain? A systematic review. J Relig Health. 2019. doi:10.1007/s10943-019-00914-7

8. Meints SM, Edwards RR. Evaluating psychosocial contributions to chronic pain outcomes. Prog Neuropsychopharmacol Biol Psychiatry. 2018;87:168-182. doi:10.1016/j.pnpbp.2018.01.017

9. Osborne TL, Jensen MP, Ehde DM, Hanley MA, Kraft G. Psychosocial factors associated with pain intensity, pain-related interference, and psychological functioning in persons with multiple sclerosis and pain. Pain. 2007;127(1):52-62. doi:10.1016/j.pain.2006.07.017

10. Sharma S, Ferreira-Valente A, de C Williams AC, Abbott JH, PaisRibeiro J, Jensen MP. Group differences between countries and between languages in pain-related beliefs, coping, and catastrophizing in chronic pain: a systematic review. Pain Med. 2020;pnz373. doi: $10.1093 / \mathrm{pm} / \mathrm{pnz} 373$

11. Humphrey JH. Human Stress: Current Selected Research. Vol. 1. AMS Press; 1984.

12. Smith CA, Wallston KA. Adaptation in patients with chronic rheumatoid arthritis: application of a general model. Health Psychol. 1992;11:151-162. doi:10.1037/0278-6133.11.3.151

13. Ferreira-Valente A, Pais-Ribeiro J, Jensen MP. Coping, depression, anxiety, self-efficacy and social support: impact on adjustment to chronic pain. Escritos de Psicologia. 2009;2(3):8-17.

14. Fordyce WE, Fowler RS, DeLateur B. An application of behavior modification technique to a problem of chronic pain. Behav Res Ther. 1968;6(1):105-107. doi:10.1016/0005-7967(68)90048-X

15. Eccleston C, Crombez G. Pain demands attention: a cognitive-affective model of the interruptive function of pain. Psychol Bull. 1999;125 (3):356-366. doi:10.1037/0033-2909.125.3.356

16. Lethem J, Slade PD, Troup JDG, Bentley G. Outline of a fearavoidance model of exaggerated pain perception-I. Behav Res Ther. 1983;21(4):401-408. doi:10.1016/0005-7967(83)90009-8
17. Vlaeyen JWS, Crombez G, Linton SJ. The fear-avoidance model of pain. Pain. 2016;157(8):1588-1589. doi:10.1097/j.pain.0000000000000574

18. Kratz AL, Molton IR, Jensen MP, Ehde DM, Nielson WR. Further evaluation of the motivational model of pain self-management: coping with chronic pain in multiple sclerosis. Ann Behav Med. 2011;41 (3):391-400. doi:10.1007/s12160-010-9249-6

19. Lazarus R, Folkman S. Stress, Appraisal, and Coping. Springer Publishing Company; 1984.

20. Thorn BE. Cognitive Therapy for Chronic Pain: A Step-By-Step Guide. Guilford Press; 2004.

21. Lazarus RS, Folkman S. Transactional theory and research on emotions and coping. Eur J Pers. 1987;1(3):141-169. doi:10.1002/per.2410010304

22. Beck J. Cognitive Behavior Therapy: Basics and Beyond. 2nd ed. Guilford Press; 2011.

23. O'Donohue WT, Fisher JE, eds. Cognitive Behavior Therapy: Core Principles for Practice. Wiley; 2012.

24. Jiménez FJR. Acceptance and commitment therapy versus traditional cognitive behavioral therapy: a systematic review and meta-analysis of current empirical evidence. Int J Psychol Psychol Ther. 2012;12:333-358.

25. Hayes SC, Strosahl KD, Wilson KG. Acceptance and Commitment Therapy: An Experiential Approach to Behaviour Change. Guilford Publications; 2003.

26. Chin F, Hayes SC. Acceptance and commitment therapy and the cognitive behavioral tradition. In: Hofmann SG, Asmundson GJG (Editors). The Science of Cognitive Behavioral Therapy. Elsevier; 2017:155-173. doi:10.1016/B978-0-12-803457-6.00007-6

27. McCracken LM, Vowles KE. Acceptance and commitment therapy and mindfulness for chronic pain: model, process, and progress. $\mathrm{Am}$ Psychol. 2014;69(2):178-187. doi:10.1037/a0035623

28. Park CL. Making sense of the meaning literature: an integrative review of meaning making and its effects on adjustment to stressful life events. Psychol Bull. 2010;136(2):257-301. doi:10.1037/a0018301

29. Park CL. The Meaning Making Model: a framework for understanding meaning, spirituality, and stress-related growth in health psychology. Eur Health Psychol. 2013;15(2):40-47.

30. Park CL, Folkman S. Meaning in the context of stress and coping. Rev Gen Psychol. 1997;1(2):115-144. doi:10.1037/1089-2680.1.2.115

31. Frankl VE. On the Theory and Therapy of Mental Disorders: AanIntroduction to Logotherapy and Existential Analysis. Brunner: Routledge; 2004.

32. Matos L, Indart M, Park CL, Leal I Meaning-making and psychological adjustment following refugee trauma. Actas Do $12^{\circ}$ Congresso Nacional de Psicologia Da Saúde; 2018:513-521. Available from: https://www. researchgate.net/publication/322802026_Meaning-making_and_psycho logical_adjustment_following_refugee_trauma. Accessed July 21, 2021

33. Bonanno G, Keltner D. Brief report. The coherence of emotion systems: comparing "on-line" measures of appraisal and facial expressions, and self-report. Cogn Emot. 2004;18(3):431-444. doi:10.1080/02699930341000149

34. Bower JE, Kemeny ME, Taylor SE, Fahey JL. Cognitive processing, discovery of meaning, CD4 decline, and AIDS-related mortality among bereaved HIV-seropositive men. J Consult Clin Psychol. 1998;66(6):979-986. doi:10.1037/0022-006X.66.6.979

35. Davis C, Wortman C, Lehman D, Silver R. Searching for meaning in loss: are clinical assumptions correct? Death Stud. 2000;24 (6):497-540. doi:10.1080/07481180050121471

36. Park CL. Religion as a Meaning-Making Framework in coping with life stress. J Soc Issues. 2005;61(4):707-729. doi:10.1111/j.15404560.2005.00428.x

37. Park CL. Testing the Meaning Making Model of coping with loss. J Soc Clin Psychol. 2008;27(9):970-994. doi:10.1521/jscp.2008.27.9.970

38. Wu L, Bonanno G, DuHamel K, et al. Pre-bereavement meaning and post-bereavement distress in mothers of children who underwent haematopoietic stem cell transplantation. $\mathrm{Br} J$ Health Psychol. 2008;13(3):419-433. doi:10.1348/135910707X204236 
39. Eton DT, Lepore SJ, Helgeson VS. Psychological distress in spouses of men treated for early-stage prostate carcinoma. Cancer. 2005;103 (11):2412-2418. doi:10.1002/cncr.21092

40. Manne S, Ostroff J, Fox K, Grana G, Winkel G. Cognitive and social processes predicting partner psychological adaptation to early stage breast cancer. Br J Health Psychol. 2009;14(1):49-68. doi:10.1348/ 135910708 X298458

41. Fife BL. The measurement of meaning in illness. Soc Sci Med. 1995;40(8):1021-1028. doi:10.1016/0277-9536(94)00174-R

42. Fife BL. The role of constructed meaning in adaptation to the onset of life-threatening illness. Soc Sci Med. 2005;61(10):2132-2143. doi:10.1016/j.socscimed.2005.04.026

43. Kernan WD, Lepore SJ. Searching for and making meaning after breast cancer: prevalence, patterns, and negative affect. Soc Sci Med. 2009;68(6):1176-1182. doi:10.1016/j.socscimed.2008.12.038

44. Almeida VM, Carvalho C, Pereira MG. The contribution of purpose in life to psychological morbidity and quality of life in chronic pain patients. Psychol Health Med. 2019;25(2):160-170. doi:10.1080/ 13548506.2019.1665189

45. Rodrigues C, Pinto P, Leal I, Pais-Ribeiro J, Jensen MP, FerreiraValente A. Everyone with pain goes to the doctor, but only some do meditation: cross-cultural comparison USA vs Portugal. Psic Saúde Doenças. 2020;21(01):45-52. doi:10.15309/20psd210108

46. Vellucci R. Heterogeneity of chronic pain. Clin Drug Investig. 2012;32:3-10. doi:10.2165/11630030-000000000-00000

47. Ferreira-Valente A, Pais-Ribeiro J, Jensen MP. Validity of four pain intensity rating scales. Pain. 2011;152(10):2399-2404. doi:10.1016/j. pain.2011.07.005

48. Cleeland C, Ryan KM. Pain assessment: global use of the Brief Pain Inventory. Ann Acad Med Singapore. 1994;23:129-138.

49. Krueger RA, Casey MA. Focus Groups: A Practical Guide for Applied Research. 5th ed. SAGE; 2015.

50. Kitzinger J. The methodology of focus groups: the importance of interaction between research participants. In: Seal C, editor. Social Research Methods: A Reader. Routledge; 2012:269-272.

51. Braun V, Clarke V. Using thematic analysis in psychology. Qual Res Psychol. 2006;3(2):77-101. doi:10.1191/1478088706qp063oa

52. Braun V, Clarke V. Thematic Analysis. In: Cooper H, Camic P, Long D, Panter A, Rindskopf D, Sher K, editors. APA Handbook of Research Methods in Psychology. Vol. 2. Research designs: Quantitative, qualitative, neuropsychological, and biological. American Psychological Association; 2012:57-71.

53. Braun V, Clarke V. Successful Qualitative Research: A Practical Guide for Beginners. SAGE; 2013.

54. Braun V, Clarke V. Reflecting on reflexive thematic analysis. Qual Res Sport Exerc Health. 2019;11(4):589-597. doi:10.1080/ 2159676X.2019.1628806

55. Costa PA, Tasker F. "We wanted a forever family": altruistic, individualistic, and motivated reasoning motivations for adoption among LGBTQ individuals. J Fam Issues. 2018;39(18):4156-4178. doi: $10.1177 / 0192513 \times 18810948$

Journal of Pain Research

\section{Publish your work in this journal}

The Journal of Pain Research is an international, peer reviewed, open access, online journal that welcomes laboratory and clinical findings in the fields of pain research and the prevention and management of pain. Original research, reviews, symposium reports, hypothesis formation and commentaries are all considered for publication. The manuscript

Submit your manuscript here: https://www.dovepress.com/journal-of-pain-research-journal
56. Fereday J, Muir-Cochrane E. Demonstrating rigor using thematic analysis: a hybrid approach of inductive and deductive coding and theme development. Int $J$ Qual Methods. 2006;5(1):80-92. doi: $10.1177 / 160940690600500107$

57. Sweeny K. Crisis decision theory: decisions in the face of negative events. Psychol Bull. 2008;134(1):61-76. doi:10.1037/00332909.134.1.61

58. Bunzli S, Smith A, Schütze R, O’Sullivan P. The lived experience of pain-related fear in people with chronic low back pain. In: van Rysewyk S, editor. Meanings of Pain. Vol. 1. Springer; 2016:227-250.

59. van Rysewyk SP. A call for study on the meanings of pain. In: van Rysewyk S, editor. Meanings of Pain. Vol. 1. Berlin Heidelberg: Springer; 2016:1-22.

60. Jensen M, Keefe FJ, Lefebvre JC, Romano JM, Turner JA. One- and two-item measures of pain beliefs and coping strategies. Pain. 2003;104(3):453-469. doi:10.1016/S0304-3959(03)00076-9

61. Vlaeyen JWS, Kole-Snijders AMJ, Boeren RGB, van Eek H. Fear of movement/(re)injury in chronic low back pain and its relation to behavioral performance. Pain. 1995;62(3):363-372. doi:10.1016/ 0304-3959(94)00279-N

62. Vlaeyen JWS, Linton SJ. Fear-avoidance and its consequences in chronic musculoskeletal pain: a state of the art. Pain. 2000;85 (3):317-332. doi:10.1016/S0304-3959(99)00242-0

63. Dezutter J, Dewitte L, Vanhooren S. Chronic pain and meaning in life: challenge and change. In: van Rysewyk S, editor. Meanings of Pain. Vol. 1. Springer; 2016:211-226.

64. Steger MF, Frazier P, Oishi S, Kaler M. The meaning in life questionnaire: assessing the presence of and search for meaning in life. J Couns Psychol. 2006;53(1):80-93. doi:10.1037/0022-0167.53.1.80

65. Tait RC, Chibnall JT. Development of a brief version of the Survey of Pain Attitudes. Pain. 1997;70(2):229-235. doi:10.1016/S03043959(97)03330-7

66. Park CL, Riley KE, George LS, et al. Assessing disruptions in meaning: development of the Global Meaning Violation Scale. Cogn Ther Res. 2016;40(6):831-846. doi:10.1007/s10608-016-9794-9

67. Park CL, George LS. Assessing meaning and meaning making in the context of stressful life events: measurement tools and approaches. $J$ Posit Psychol. 2013;8(6):483-504. doi:10.1080/17439760.2013.830762

68. American Psychological Association. APA dictionary of psychology. APA dictionary of psychology; 2020. Available from: https://diction ary.apa.org/logotherapy. Accessed June 16, 2021.

69. Vos J, Vitali D. The effects of psychological meaning-centered therapies on quality of life and psychological stress: a metaanalysis. Palliat Support Care. 2018;16(5):608-632. doi:10.1017/ S1478951517000931

70. van der Spek N, Vos J, van Uden-kraan CF, et al. Efficacy of meaning-centered group psychotherapy for cancer survivors: a randomized controlled trial. Psychol Med. 2017;47 (11):1990-2001. doi:10.1017/S0033291717000447 management system is completely online and includes a very quick and fair peer-review system, which is all easy to use. Visit http:// www.dovepress.com/testimonials.php to read real quotes from published authors. 